\title{
VARIATION OF ICE VELOCITY AT LEWIS GLACIER, MOUNT KENYA, KENYA: VERIFICATION MIDWAY INTO A FORECAST
}

\author{
By Phillip Kruss and Stefan Hastenrath \\ (Department of Meteorology, University of Wisconsin-Madison, Madison, Wisconsin 53706, \\ U.S.A.)
}

\begin{abstract}
Aвstract. The ice velocity slowdown occurring at Lewis Glacier, Mount Kenya, during the twentieth century has continued beyond 1978. In an earlier paper, a surface velocity decrease approaching $50 \%$ was predicted between 1978 and 1985. Measurements to January 1982, halfway through the period, reveal trends generally in line with this forecast; a velocity reduction of order $20 \%$ has taken place. The mass flux decreased by at least $25 \%$. Intra-annual variability in velocity pattern and magnitude is apparent; comparatively rapid values occur during the January-February dry season.
\end{abstract}

RÉSumé. Variation de la vitesse de la glace dans le Lewis Glacier au Mont Kenya, Kenya: vérification à miparcours d'une prévision. Le ralentissement de la vitesse du Lewis Glacier au Mont Kenya au cours du 20ème siècle a continué depuis 1978. Dans un précédent article une diminution de la vitesse de surface de près de $50 \%$ avait été prévue entre 1978 et 1985. Des mesures de janvier 1982 à mi-course de cette période, révèlent des tendances générales en accord avec cette prévision; une réduction de la vitesse de l'ordre de $20 \%$ a été constatée. Le flux matériel a diminué d'au moins $25 \%$. La variabilité intra-annuelle dans le comportement des vitesses et leur ordre de grandeur est mise en évidence; les valeurs relativement rapides se situent durant la saison sèche de janvier-fëvrier.

Zusammenfassung. Geschwindigkeitsänderung an Lewis Glacier, Mount Kenya, Kenya: Bestätigung nach halbem Vorhersagezeitraum. Die Verlangsamung der Eisfliessgeschwindigkeit am Lewis Glacier, Mount Kenya, während des 20. Jahrhunderts dauert über 1978 hinaus an. In einer früheren Veröffentlichung wurde eine Geschwindigkeitsabnahme von nahezu 50\% über den Zeitraum 1978 bis 1985 vorausgesagt. Messungen bis 1982, also über den halben Vorhersagezeitraum, zeigen eine mit der Prognose übereinstimmende Entwicklung an: die Geschwindigkeit hat um etwa 20\% und der Massenfluss um wenigstens 25\% abgenommen. Es deutet sich ein Jahresgang der Eisbewegung an, derart dass vergleichsweise hohe Geschwindigkeiten während der Trockenmonate Januar-Februar auftreten.

\section{INTRODUCTION}

The surface velocity at Lewis Glacier, Mount Kenya (lat. $0^{\circ} 9^{\prime}$ S., long. $37^{\circ} 19^{\prime}$ E.), has been slowly decreasing thoughout the twentieth century (Hastenrath and Kruss, 1982). With respect to velocity observations in 1978, Hastenrath and Kruss (1982) predicted further major velocity reduction into the 1980 's, with the velocity by 1985 being decreased by an amount "approaching half the 1978 values". Expeditions during December 1979 to January 1980 and December 1981 to January 1982 have provided further velocity measurements. In the present paper development towards the Hastenrath and Kruss (1982) predictions is verified by comparison of 1978 values with subsequent observations up to the January 1982 midway mark.

\section{Observation}

The annual velocity values on which the prediction of future behavior was based (Hastenrath and Kruss, [1981]) were obtained from surveys of stakes during 25-29 January 1978, and 28 December 1978 to 5 January 1979, and are henceforth referred to as 1978 velocities. At the beginning of this interval velocities over one month, namely from 25-29 January 1978 to 24-26 
February 1978 (henceforth Feb 78), were also obtained; these Feb 78 velocities are included in part in the 1978 composite of Hastenrath and Kruss ([1981]). Further, Hastenrath and Kruss (1982) present two-year mean values measured over the 23 months separating 25-29 January 1978 and 26-27 December 1979 (henceforth 78/79).

Further surveys of the stakes during December 1981 and January 1982 have led to two-year mean velocities for the period 26-27 December 1979 to 25-26 January 1982 (henceforth 80/81) and one-month values over 29-30 December 1981 to 25-26 January 1982 (henceforth Jan 82). The measured velocities obtained for these two epochs are included in the map (Fig. 1).

\section{Velocity pattern}

The pattern seen from the velocities in Figure 1 is overall very similar to that of 1978 and 78/79 (Hastenrath and Kruss, [1981], 1982), though the values are in general less (see Section 5). Exceptions to this slowdown are the two comparatively high Jan 82 velocity values near the middle of the line defined by points L2 and L3, where the glacier is deepest (Bhatt and others, [1982]). The occurrence of relatively high velocities in January and February is discussed in Section 4 . Though the possibility for major random error cannot be ruled out with surveys over the short time interval of one month, the close proximity of location of these two high values and the general agreement between the velocity directions for 80/81 and $\mathrm{Jan} 82$ (mean difference $10^{\circ}$ ) lends validity to these one-month values.

For both data sets given in Figure 1, velocity profiles along the longitudinal line defined in Figure 1 are given in Figure 2. Further, Figure 2 includes plots for the earlier periods discussed in the preceding Section 2. The raw data in Figure 2 also have been filtered using averaging over $150 \mathrm{~m}$ intervals to remove the high-frequency component while preserving the mean velocity. The filtered versions of the Figure 2 profiles are shown in Figure 3. These curves highlight largescale features of the longitudinal velocity profile and are also compatible with the modeling results of Hastenrath and Kruss (1982).

Transverse velocity profiles along a line defined by the control points L2 and L3 (Fig. 1) are given in Figure 4 for the various one-month and two-year mean cases. Note that for the profiles in Figures 2 to 4 , every relevant data value is plotted. However, only locations having information for both epochs are linked by lines. This was done to highlight differences between pairs of curves due to velocity change with time.

\section{INTRA-ANNUAL VARIABILITY}

It is relevant to consider significant intra-annual variation which has become apparent from a comparison of the one-month curves of Figure $2 \mathrm{a}$ with the two year mean profiles of Figure $2 \mathrm{~b}$. There is considerably more scatter for Feb 78 and Jan 82 than for the two-year averages. This may in part result from such factors as the larger relative errors possible with short-term surveys and the reduction of any intra-annual effects in the calculation of two-year means. The existence of significant intra-annual variability is suggested as identifiable features occur in both of the raw-data one-month curves (Fig. 2a), except for the terminus region where the change of surface topography with time is a maximum. Further, the filtered forms of the one-month profiles given in Figure 3a show strong shape similarities; the filtering process tends to reduce the effect of random surveying errors. 


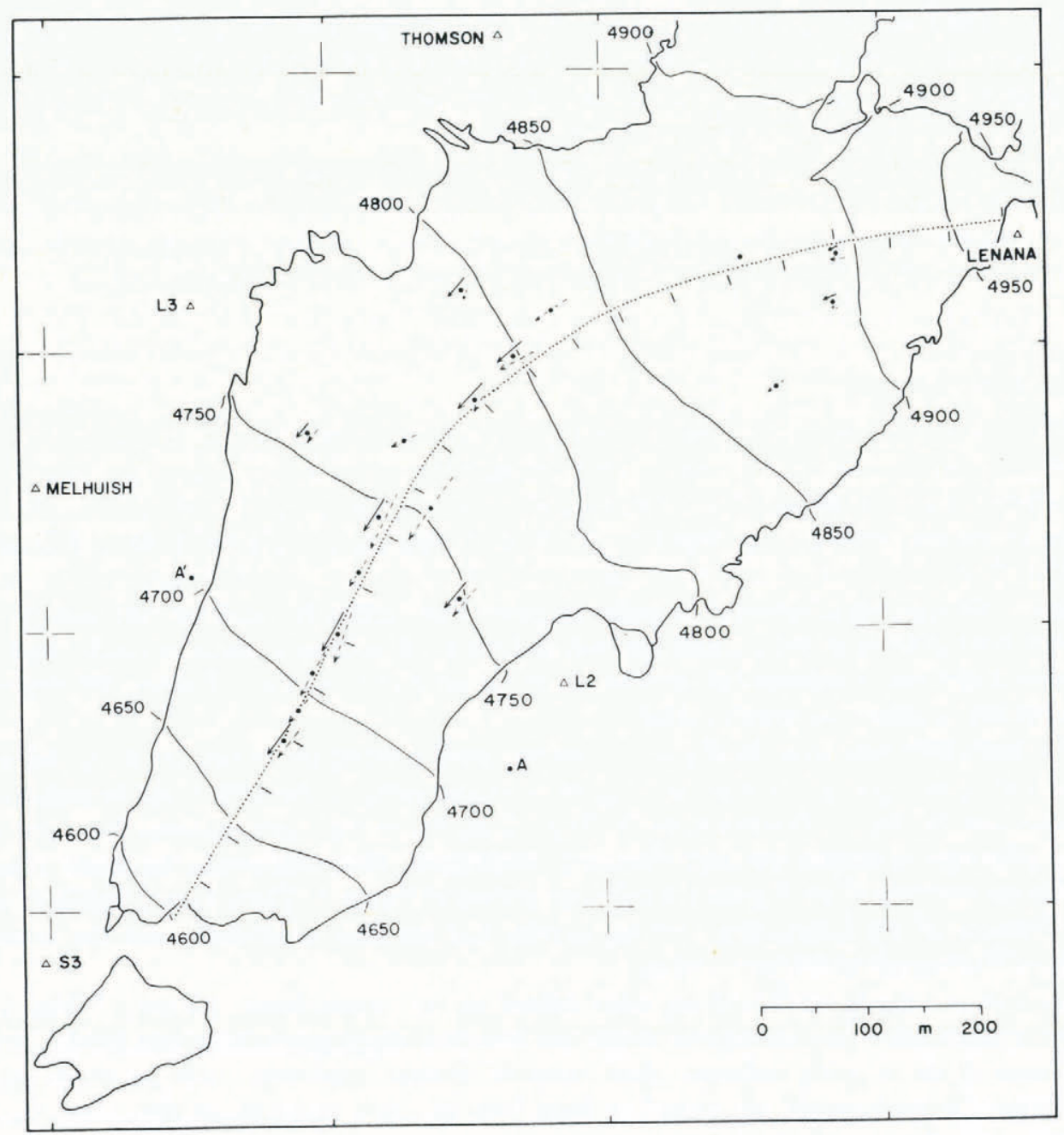

Fig. 1. Surface velocity map of Lewis Glacier. Arrows indicate the magnitude and direction of the horizontal ice velocity resulting from surveys over two intervals. Dashed and solid arrows give two-year mean velocities for 80/81 (26-27 December 1979 to 25-26 January 1982) and one month values over Jan 82 (29-30 December 1981 to 25-26 January 1982), respectively. All velocities are converted to $\mathrm{m} \mathrm{a}^{-1}$ and positions (dots) are for 25-26 January 1982. The base map at scale 1:7500 is the 1978 glacier and the dotted line defines a central longitudinal line.

The Feb 78 and Jan 82 profiles both exhibit velocity maxima which are greater than those for $78 / 79$ and $80 / 81$ (compare Figs $2 a$ and $b$, and $3 a$ and $b$ ); this difference is more striking in regard to the Jan 82 curve as it runs counter to the trend suggested by the change from $78 / 79$ to $80 / 81$. Further, these maxima are positioned farther up-glacier for the one-month (between 675 and $700 \mathrm{~m}$ down the central line for Fig. 3a) than for the two-year profiles (around $775 \mathrm{~m}$ in Fig. 3b). 


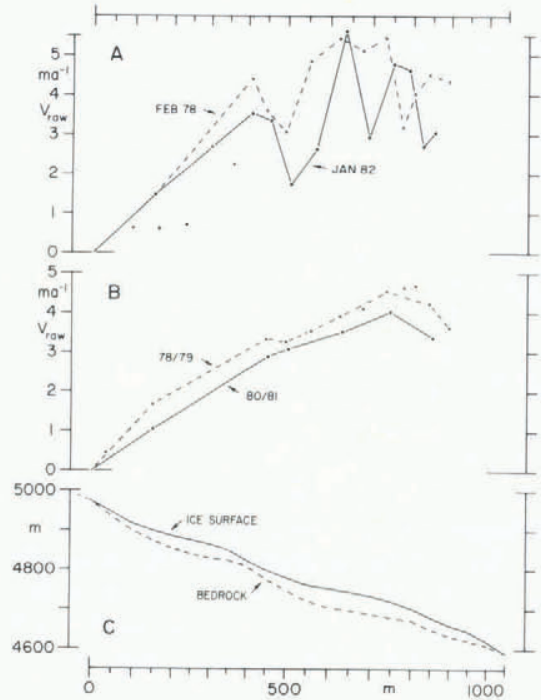

Fig. 2. Longitudinal profiles of horizontal surface velocity (raw data): (a) Velocities measured over one month during Feb 1978 (25-29 January 1978 to 24-26 February 1978; crosses, dashed line) and Jan 82 (29-30 December 1981 to 25-26 January 1982; dots, solid). (b) Two-year mean velocities for 78/79 (25-29 January 1978 to 26-27 December 1979; crosses, dashed) and 80/81 (26-27 December 1979 to 25-26 January 1982; dots, solid). (c) Longitudinal profiles of 1978 surface elevation (solid) and bedrock (dashed). All profiles are with respect to down-glacier distance along the central line defined in Figure 1. To aid in the comparison of differing epochs, only locations with velocity data at both times are connected.

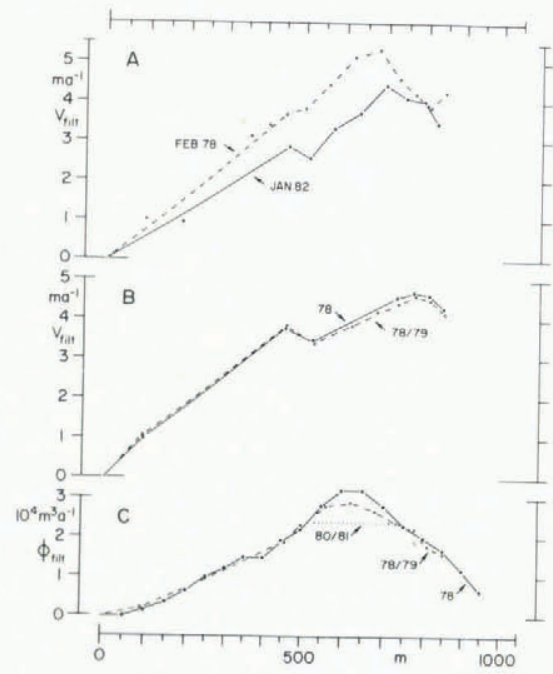

Fig. 3. Longitudinal profiles of horizontal surface velocity and mass flux (filtered): (a) filtered velocities over one month for Feb 78 (25-29 January 1978 to 24-26 February 1978; crosses, dashed line) and Jan 82 (29-30 December 1981 to 25-26 January 1982; dots, solid); (b) filtered twoyear mean velocities for 78 (25-29 January 1978 to 28 December 1978 - 5 January 1979; dots, solid) and for 78/79 (25-29 January 1978 to 26-27 December 1979; crosses, dashed); (c) filtered mass fluxes for 1978 (modelled annual, dots, solid), 78/79 (crosses, dashed), and 80/81 (26-27 December 1979 to 25-26 January 1982; dotted) in waterequivalent units. The $80 / 81$ line gives the bestestimate magnitude of the $80 / 81$ maximum mass flux and also defines the boundaries of its location. All profiles are with respect to down-glacier distance along the central line defined in Figure 1. Only locations with velocity data at both times are connected; all mass flux points are connected.

The transverse profiles of Figure 4 also demonstrate the difference in form between onemonth (Fig. 4a) and two-year (Fig. 4b) velocities. The Feb 78 and Jan 82 curves are decidedly more peaked than those of $78 / 79$ or $80 / 81$; the ratio of cross-section mean surface velocity to cross-section maximum velocity is 0.6 for Feb 78 as compared to 0.7 for $78 / 79$.

The variation in velocity over the year may be due in part to change in the contribution of basal sliding. This is suggested by the fact that the glacier mean and maximum velocities were faster in Jan 82 than for $80 / 81$ despite the surface lowering of a few meters which occurred over $80 / 81$. Further, with respect to the two-year maxima, the maxima for the single months are shifted away from a region of steeper slope into the area of deepest ice. The months January and February are at the height of the dry season when melt water production at Lewis Glacier is greatest. 


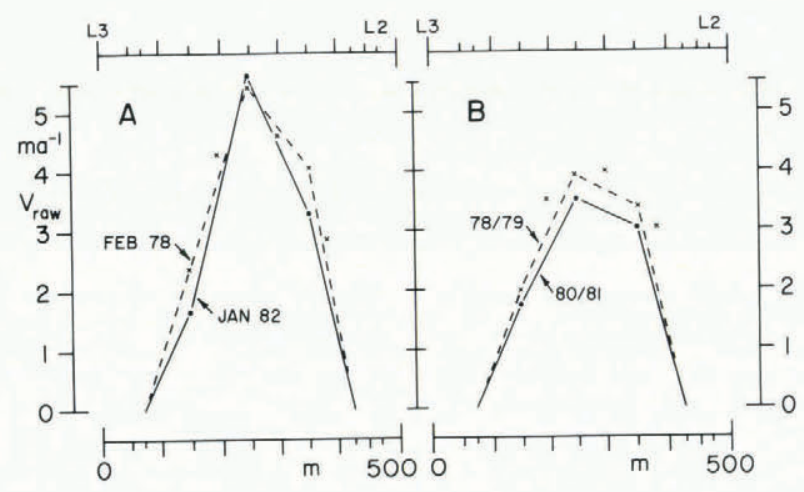

Fig. 4. Transverse profiles of horizontal surface velocity (raw): (a) Velocities over one month for Feb 78 (25-29 January 1978 to 24-26 February 1978; crosses, dashed line) and Jan 82 (29-30 December 1981 to 25-26 January 1982; dots solid). (b) Two-year mean velocities for 78/79 (25-29 January 1978 to 26-27 December 1979; crosses, dashed) and 80/81 (26-27 December 1979 to 25-26 January 1982; dots, solid). All profiles are along a line between control points L3 and L2 in Figure 1; distance is from L3. Only locations with velocity data at both times are connected.

This apparent intra-annual variability in velocity is important in the context of the Hastenrath and Kruss (1982) velocity forecast which is based on 1978 annual data. Though the one-month values can be compared amongst themselves to identify trends, they cannot be used to produce changes in magnitude or position of the velocity maximum which would be comparable with annual data, nor can one-month mean magnitudes be directly compared with the $78 / 79$ or $80 / 81$ data or with the 1978 annual values.

\section{VERIFICATION}

Hastenrath and Kruss (1982) made several predictions concerning the change in velocity and mass flux to be expected into the mid 1980's. They suggested that between 1978 and 1985: (i) a major overall decrease in the annual surface velocity would occur, with the velocity by 1985 reduced by an amount approaching half the 1978 values; (ii) the velocity maximum would become less sharply defined and move quite significantly up-glacier (up to $100 \mathrm{~m}$ ); and (iii) the maximum annual mass flux would decrease greatly (to less than half that in 1978) but its position move less than $50 \mathrm{~m}$ up-glacier.

Change to 1985 was computed by Hastenrath and Kruss (1982) using the net balance for the March 1979 to March 1980 budget year for which the glacier average was of $-180 \mathrm{~cm}$ water equivalent. It was felt that this net balance constituted a somewhat extreme case for present conditions, and predictions were made less extreme than the calculated results. The net balance conditions in March 1979 to March 1980 were indeed more extreme than during the 1978/79, $1980 / 81$, and 1981/81 budget years, for which water-equivalent net balance values of -10 , -120 , and $-37 \mathrm{~cm}$ were obtained.

\section{(i) Velocity decrease}

Profile average velocities for the curves in Figures 2 and 3 are presented in Table I for the various comparable time intervals. 
TABle I. MEAN VElocity AND MAXIMUM MASS FLUX

(a) Longitudinal mean velocities defined by the lines in Figures 2 and 3 and the percentage decrease between epochs. (b) Maximum mass fluxes in liquid water equivalent estimated and corresponding net reduction since 1978 . For definitions of time periods see text Section 2.

\begin{tabular}{lcccc} 
& \multicolumn{2}{c}{ (a) Mean velocity } & \multicolumn{2}{c}{ (b) Maximum mass flux } \\
& $\mathrm{cm} \mathrm{a} \mathrm{a}^{-1}$ & $\%$ & $10^{3} \mathrm{~m}^{3} \mathrm{a}^{-1}$ & $\%$ \\
Feb 78 & 334 & & & \\
Jan 82 & 272 & 19 & & \\
1978 & 299 & & 32 & 9 \\
$78 / 79$ & 297 & 1 & 29 & \\
$78 / 79$ & 290 & & & 25 \\
$80 / 81$ & 244 & 16 & 24 &
\end{tabular}

The maximum time period separating comparable observations since 1978 is the almost four years between the one-month values for Feb 78 and Jan 82, which is somewhat more than half the seven-year forecast interval. The velocity reduction over this interval amounts to $19 \%$, well on the way towards the decrease approaching $50 \%$ forecast for 1985 .

Turning to 1978 annual velocities and the two-year mean values, Figure $3 \mathrm{~b}$ compares the filtered 1978 and $78 / 79$ profiles. Note that the 1978 curve in Figure $3 \mathrm{~b}$ is very similar to the 1978 modeled profile in Hastenrath and Kruss (1982, fig. 2), and hence provides the link between the secular variation up to 1978 discussed by Hastenrath and Kruss (1982) and changes occurring since then. The time elapsed between the mid-point of these two observation periods is less than six months (Table I), and the velocity decrease is only about one per cent.

For the mean 78/79 and 80/81 velocities derived from the areas under the lines in Figure $2 b$, a velocity reduction of about $16 \%$ is obtained (Table I). These data are representative of conditions throughout the four years 1978 to 1981 and the mid-points of the two intervals are separated by two years. If this trend continued over the remaining years to 1985 , the net decrease in surface velocity would equal $55 \%$.

\section{(ii) Velocity maximum}

There is little to be concluded concerning change in magnitude and location of annual velocity maximum, partly because of the intra-annual variability discussed in Section 3. Also, the spacing of data points in the region of the maximum had degenerated for 80/81 to an extent which no longer allows identification of the maximum velocity with sufficient magnitude or spatial resolution.

Comparing the 1978 and 78/79 curves (Fig. 3b; see also Hastenrath and Kruss, 1982), significant decrease in the maximum is seen over this very short elapsed time. However, there is also an indication of a shift of the maximum down-glacier, contrary to prediction. During the most recent trip to Lewis Glacier in December 1981 to January 1982, the network of stakes inserted into the ice was completely refurbished, particularly in the neighborhood of the velocity maximum. New stakes were drilled in as much as ten metres and should provide good coverage at least through 1985.

(iii) Mass flux

Figure 3 and Table I contain the mass fluxes calculated for 1978, 78/79, and 80/81. The 
1978 profile in Figure 3 is that given in Hastenrath and Kruss (1982) and thus provides the link for mass flux between earlier secular change and more recent variation. While a comparable flux curve has been derived for $78 / 79$ (Fig. 3c), this was not possible for $80 / 81$ due to insufficient velocity observations. However, the maximum mass flux for this latter period was estimated, and this value, along with its spatial range, is also included in Figure $3 \mathrm{c}$.

Hastenrath and Kruss (1982) expected the maximum mass flux to decrease more than the velocity but also that its continuing movement up-glacier would be less. The net reduction of maximum mass flux over 1978 to $80 / 81$ is $25 \%$, compared with somewhat more than $15 \%$ for velocity (Table I); the decrease between the two-year $78 / 79$ and $80 / 81$ flux maxima is also somewhat more than $15 \%$. The total flux change observed is a very significant proportion of the range by 1985 given in Hastenrath and Kruss (1982), i.e. up to less than half that in 1978.

\section{Concluding Remarks}

Hastenrath and Kruss (1982) predicted the general velocity reduction found during the 1900's for Lewis Glacier would continue after 1978, with comparatively large relative change taking place in both velocity and mass flux to 1985 . By about midway through this seven-year period, surface velocity decrease of order $20 \%$ has been observed, a significant portion of the decrease of approaching 50\% forecast for 1985. A reduction in the maximum mass flux of about $25 \%$ has also been estimated for a somewhat shorter interval. Change in magnitude and location of both velocity and flux maxima could not be indentified because of deterioration of the stake network. The complete renewal of this network which took place during the December 1981 to January 1982 field season should ensure the possibility of obtaining spatially detailed velocity information to the 1985 forecast endpoint.

\section{ACKNOWLEDGEMENTS}

This study was authorized by the Office of the President, Republic of Kenya, and supported by the U.S. National Science Foundation through grants EAR76-1888 and EAR 79-23897, and the United Nations Environment Programme.

MS. received 18 June 1982

\section{REFERENCES}

Bhatt, N., and others. [1982.] Ice thickness determination at Lewis Glacier, Mount Kenya: seismology, gravimetry, dynamics, by N. Bhatt, S. Hastenrath, and P. Kruss. Zeitschrift für Gletscherkunde und Glazialgeologie, Bd. 16, Ht. 2, 1980, p. 213-28.

Hastenrath, S., and Kruss, P. [1981.] Dynamics of crevasse pattern at Lewis Glacier, Mount Kenya. Zeitschrift für Gletscherkunde und Glazialgeologie, Bd. 15, Ht. 2, 1979, p. 201-07.

Hastenrath, S., and Kruss, P. 1982. On the secular variation of ice flow velocity at Lewis Glacier, Mount Kenya, Kenya. Journal of Glaciology, Vol. 28, No. 99, p. 333-39. 